\section{별난 강입자}

DOI: $10.3938 /$ PhiT. 28.002

\section{Exotic Hadrons}

Hyun-Chul KIM, Seung-il NAM and Sungtae CHO

Exotic hadrons are distinguished from conventional hadrons, whose usual baryons consist of three quarks and ordinary mesons consist of a quark and an anti-quark. A baryon containing five quarks is called a pentaquark whereas a meson that consists of two quarks and two anti-quarks is dubbed a tetraquark. Also, a hadron that is composed of quarks and gluons exists and is known as a hybrid exotic hadron. In the present article, we briefly review the history of exotic hadrons and recent experimental and theoretical activities to understand their structure. In particular, we explain, in layman's terms, the newly found exotic hadrons reported by researchers at accelerator facilities throughout the world, some of which contain both heavy and light quarks or consist of conventional hadrons as a molecular state.

별난 강입자는 쿼크 세 개로 이루어진 중입자나 쿼크와 반 쿼크로 되어있는 중간자와는 구조가 완전히 다른 새로운 강입 자다. 이 중에서 쿼크 다섯 개가 만드는 중입자를 펜타쿼크라 고 부르고, 쿼크 둘, 반쿼크 둘로 되어있는 중간자를 테트라쿼 크라고 한다. 그리고 쿼크와 글루온으로 이루어진 것은 하이브 리드 강입자라고 부른다. 이 글에서는 별난 강입자의 역사를

\section{저자약력}

김현철 교수는 인하대 물리학과에서 이학사, 석사, 독일 Bonn대학교에서 이학 박사를 한 뒤 Bochum Ruhr대학교에서 연구원으로 지낸 후, 1998년 부산대 물리학과를 거쳐 2008년부터 인하대학교 물리학과에 재직하고 있다. (hchkim@inha.ac.kr)

남승일 교수는 부산대 물리학과에서 이학사, 석사, 일본 Osaka대학교에서 이 학박사를 취득한 뒤 YITP(일본), KIAS(한국) 연구원을 거쳐 2013년부터 현재 까지 부경대학교 물리학과에 재직하고 있다.

조성태 교수는 미국 뉴욕주립대학(스토니브룩)에서 박사학위 취득 후, 연세대 학교 연구원을 거쳐 2014년부터 강원대학교 과학교육학부 교수로 재직 중이 다.

\section{김현철·남승일·조성태}

간략하게 설명한 다음, 오늘날 이 입자들의 구조를 이해하려고 이론과 실험에서 어떤 노력을 하고 있는지 살펴본다. 특별히 세계적인 가속기 연구소에서 발견하고 있는 강입자 중에서 무 거운 쿼크를 포함하고 있으면서 쿼크를 여럿 포함하고 있거나, 다른 강입자들의 분자상태로 존재하는 강입자를 쉬운 말로 설 명한다.

\section{$\Theta^{+}$의 간략한 역사}

물질이란 무엇인가? 이 질문은 오래전부터 물리학자들이 마 음속에 품어온 질문이다. 우주가 시작되면서 물질이 어떻게 생 겨났는지, 그리고 양성자와 중성자는 어떻게 태어나서 가벼운 핵을 이루고, 별을 만들고, 다시 별에서 무거운 핵을 만들고, 궁극에는 우주에 존재하는 모든 원소를 만들게 되었는지, 아직 다 모른다. 원소를 이루는 원자핵 속에는 양성자와 중성자가 있다. 그리고 이 양성자와 중성자는 다시 세 개의 쿼크로 이루 어진다. 양성자는 위 쿼크 두 개와 아래 쿼크 하나, 중성자는 반대로 아래 쿼크 두 개와 위 쿼크 하나로 되어 있다. 양성자 와 중성자는, 통칭해서 핵자라고 부른다. 핵자들 사이에는 파 이중간자가 쉴 새 없이 생겼다가 없어지길 반복한다. 이 파이 중간자는 위 쿼크나 아래 쿼크 하나와 위 또는 아래 반쿼크 하나로 이루어진다. 그리고 핵자 안에 있는 쿼크 사이에서는 무수히 많은 글루온이 생겼다가 없어졌다 하기를 끊임없이 되 풀이한다.

양성자가 기묘쿼크와 반 기묘쿼크가 생겨날 정도로 에너지를 받으면, 하이퍼론과 케이온이 생겨나기도 하는데, 하이퍼론도 대부분은 핵자처럼 쿼크 세 개로 이루어져 있고, 케이온도 파 이온처럼 가벼운 쿼크 하나와 반 쿼크 하나로 되어있다. 이렇 게 핵자나 파이온을 닮은 중입자와 중간자를 통칭해서 종래의 강입자(conventional hadrons)'라고 부른다. 1964년 2월, 머레 이 겔만(Murray Gell-Mann)이 Physics Letters에 <중입자와 중간자의 개략적인 모형>이라는 제목으로 두 쪽 밖에 안 되지 만, 기념비적인 논문을 출판한다. ${ }^{[1]} \mathrm{SU}(3)$ 군의 표현에 따라 그 때까지 발견된 하이퍼론과 중간자를 분류하였다. 겔만은 동시 에 수학적으로 쿼크 네 개와 반 쿼크 하나 $(q q q q \bar{q})$ 로 된 중입 


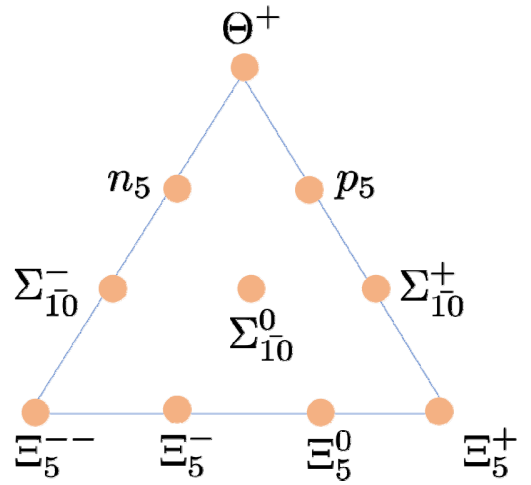

Fig. 1. Representation of the SU(3) baryon antidecuplet $(\overline{10})$.

자가 존재할 수도 있고, 쿼크 두 개와 반 쿼크 두 개 $(q q \bar{q} \bar{q})$ 로 이루어진 중간자도 존재할 수 있다는 말을 했다. 이 다섯 개의 쿼크로 이루어진 중입자를 펜타쿼크라고 부르고, 네 개의 쿼크 로 만들어진 중간자를 테트라쿼크라고 부른다. 양자색소역학이 세상에 나온 뒤로는 글루온만으로 되어있는 글루온 공(gueball) 과 쿼크 두 개와 글루온으로 이루어진 중간자, 또는 쿼크 세 개와 글루온이 주로 들어있는 중입자 같은 별난 하이브리드 강입자(exotic hybrid hadrons)의 존재도 사람들의 관심을 끌 고 있다.

1960년대까지만 해도 이런 별난 강입자는 그저 수학적으로 만 가능할 뿐이지, 자연에 존재할 거라고는 여기지 않았다. 하 지만 1970년대 후반까지 세기도 힘들 정도로 많은 강입자가 발견되자, 이런 별난 입자들도 존재할 가능성이 있다는 말이 물리학자들 사이에 나왔다. 그래도 이런 입자들의 존재 여부를 심각하게 따져보기 시작한 것은 2000년대 들어와서부터였다. 1997년에 드미트리 디아코노프(Dmitri Diakonov), 빅토르 페 트로프(Victor Petrov), 막심 폴야코프(Maxim Polyakov), 이 세 명의 러시아 물리학자가 $\mathrm{SU}(3)$ 표현 중에서 반십중항(antidecuplet) 중입자에 관한 논문을 출판하였다. ${ }^{[2]}$

이 반십중항은 자연스럽게 쿼크 네 개와 반 쿼크 하나로 이 루어진, 열 개의 펜타쿼크로 이루어져 있다. 그 중에서도 아이 소스핀 단일항이면서, 기묘도가 +1 인 펜타쿼크는 특별했다. 중입자 중에서 기묘도가 +1 인 입자는 이 중입자밖에 없다. 처음에 이 중입자는 $Z^{+}$라고 불렸다. 그러나 입자들의 이름은 대부분 그리스어 문자에서 따왔기 때문에 이 중입자의 이름도 거기서 따오는 게 더 바람직하다고 여겼다. 그런데 다 쓰고, 하나 남은 문자가 $\Theta$ 였기 때문에 디아코노프는 $Z^{+}$를 $\Theta^{+}$로 개칭하였다. 2001년 2월에 오스트레일리아에서 열린 Quark Nuclear Physics 워크솝에서 디아코노프는 일본 오사카대학 핵물리연구소에 있는 나카노 타카시를 만나 펜타쿼크 $\Theta^{+}$를 측정할 수 있는지 제안했다. 그리고 2003년, 일본 효고현에
있는 방사광 가속기 SPring-8에서 나카노가 이끄는 LEPS (Laser Electron Photon Experiment at SPring-8) 실험 그룹 에서 질량이 $1540 \mathrm{MeV}$ 쯤 되는 근처에서 $\Theta^{+}$를 발견하였다 고 발표하였다. ${ }^{[3]}$ 그리고 얼마 지나지 않아 미국 제퍼슨 연구 소에 있는 CLAS(CEBAF Large Acceptance Spectrometer) 연구 그룹에서도 $\Theta^{+}$의 발견을 알렸다. ${ }^{[4]}$

두 연구 그룹에서 쿼크가 다섯 개로 이루어진 입자를 최초 로 발견했다는 소식은 주요 신문과 방송을 통해 전 세계에 알 려졌다. 다른 가속기 센터에 있는 실험 그룹에서도 서둘러 이 미 존재하는 실험 데이터를 해석했는데, 과연 $\Theta^{+}$가 존재한다 는 사실을 보고했다. 그러나 고에너지 실험에서는 $\Theta^{+}$의 증거 를 찾을 수 없다고 했다. CERN에 있는 NA49 실험에서는 $\Theta^{+}$외에도 또 다른 펜타쿼크 중입자인 $\Xi_{5}$ 가 존재한다는 논 문을 발표했지만, 이 결과를 검증하는 후속 실험결과에서는 이 중입자의 존재 여부를 확인하지 못했다. ${ }^{[5]}$

그런데 2006년에 반전이 일어났다. 제퍼슨 연구소의 CLAS 실험 그룹에서는 $\Theta^{+}$만을 찾기 위한 실험을 새로 해서 기존 데이터보다 두 배 넘는 데이터를 분석했다. ${ }^{[6]}$ 결과는 의외였다. $\Theta^{+}$가 보이지 않는 것이었다. 후속 실험도 마찬가지였다. 이 실험은 대단히 충격적이었다. 이어서 일본 고에너지연구소 (KEK)에서도 파이온 빔을 이용해서 $\Theta^{+}$를 찾으려고 애썼지만, 결과는 부정적이었다. 결국, Particle Data Group에서 정리해 놓은 Particle Data Book에 잠시 실렸던 $\Theta^{+}$는 2008년 판에 서 빠지게 되었다. 일본 LEPS 실험 그룹과 러시아 DIANA 그 룹에서는 여전히 $\Theta^{+}$가 존재한다는 실험결과를 발표했지 만, ${ }^{[7,8]}$ CLAS 실험 그룹에서 발표한 부정적인 결과 이후로는 $\Theta^{+}$에 관한 논문은 거의 나오지 않았다. CLAS 실험에 속한 실험물리학자들 일부가 $\phi$ 중간자와 $\Theta^{+}$의 간섭 패턴을 연구

\section{REFERENCES}

[1] M. Gell-Mann, Phys. Lett. 8, 214 (1964).

[2] D. I. Diakonov, V. Petrov and M. V. Polyakov, Z. Phys. A 359, 305 (1997).

[3] LEPS Collaboration (T. Nakano et al.), Phys. Rev. Lett. 91, 012002 (2003)

[4] CLAS Collaboration (S. Stepanyan et al.), Phys. Rev. Lett. 91, 252001 (2003).

[5] NA49 Collaboration (C. Alt et al.), Phys. Rev. Lett. 92, 042003 (2004)

[6] CLAS Collaboration (B. McKinnon et al.), Phys. Rev. Lett. 96, 212001 (2006).

[7] LEPS-\|l Collaboration (Nakano et al.), Phys. Rev. C 79, 025210 (2009).

[8] DIANA Collaboration (Barman et al.), Phys. Rev. C 89, 045204 (2014). 


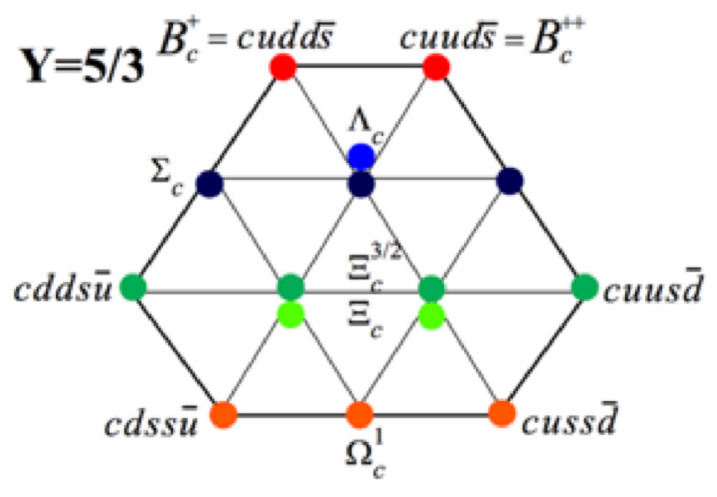

Fig. 2. Representation of the SU(3) baryon antidecapentaplet $(\overline{15})$.

해서 $\Theta^{+}$중입자가 존재한다는 걸 발표했지만, ${ }^{[9]}$ 대세를 바꾸 기에는 역부족이었다.

$\Theta^{+}$의 존재 여부에 종지부를 찍기 위해서는 광자를 이용한 광생성 과정보다는 케이온을 직접 중양자에 때려서 $\Theta^{+}$를 생 성시킬 수 있는지 살펴보는 실험이 가장 적당하다. 이 실험은 현재 일본 양성자 가속기 연구센터(J-PARC)에서 할 수 있고, $\Theta^{+}$에 관한 한, 최종실험이라고 부를 수 있을 만큼 중요한 실 험이지만, 현재는 $\Theta^{+}$연구에 대한 동력을 많이 상실한지라 앞으로 관련 실험을 수행할지 불투명한 상태다.

\section{무거운 쿼크를 지닌 펜타쿼크}

2015년, CERN에 있는 $\mathrm{LHCb}$ 실험에서 $P_{c}$ 라고 부르는 새 로운 중입자 두 개를 발견하였다. ${ }^{[10]}$ 하나는 $P_{c}(4380)$ 이고, 다 른 하나는 $P_{c}(4450)$ 이다. 특이한 점은 $P_{c}(4380)$ 의 붕괴폭이 $205 \mathrm{MeV}$ 로 무척 넓지만, $P_{c}(4450)$ 은 $30 \mathrm{MeV}$ 정도밖에 되지 않는다. 이 $\mathrm{LHCb}$ 실험 결과는 소강상태에 접어들었던 펜타쿼 크 연구에 활력을 불어넣었다. 이 무거운 펜타쿼크 중입자는 $\Lambda_{b}$ 가 $J / \psi$ 와, 케이온, 양성자로 붕괴할 때 $J / \psi$ 와 양성자를 묶은 채널에서 발견하였기 때문에 $P_{c}$ 가 주로 붕괴하는 채널은 $J / \psi$ 와 $p$ 가 될 것이다. 따라서 $P_{c}$ 는 $\Theta^{+}$처럼 쿼크의 색소가 얽혀있는 펜타쿼크라기 보다는, $J / \psi$ 와 양성자의 분자상태로 이해할 수도 있다. 하지만 $P_{c}$ 의 내부 구조를 정량적으로 이해 하기 위해서는 $\bar{D} \Lambda_{c}^{+}$나 $\bar{D} \Sigma_{c}, \overline{D^{*}} \Lambda_{c}$ 같은 채널의 기여도가 있을 수도 있다.

2017년에는 $\mathrm{LHCb}$ 실험 그룹에서 지금까지 본 적이 없는, 다섯 개의 들뜬 $\Omega_{c}$ 를 발견하였다. ${ }^{[1]}$ 즉, $\Omega_{c}(3000), \Omega_{c}(3050)$, $\Omega_{c}$ (3066), $\Omega_{c}$ (3090), $\Omega_{c}$ (3119)를 얻었고, $3180 \mathrm{MeV}$ 보다 더 높은 에너지에서 몇 개의 융기 구조도 발견하였다. 이 다섯 개
중에서 $\Omega_{c}(3119)$ 를 제외하고, 나머지 네 개의 $\Omega_{c}$ 는 Belle 실 험에서도 확인하였다. 이 다섯 개의 $\Omega_{c}$ 중에서 $\Omega_{c}(3050)$ 과 $\Omega_{c}(3119)$ 는 다른 $\Omega_{c}$ 에 비해 붕괴폭이 표가 날 정도로 작다. $\Omega_{c}(3050)$ 의 붕괴폭은 $0.8 \mathrm{MeV}$ 이고, $\Omega_{c}(3119)$ 는 $1.1 \mathrm{MeV}$ 밖에 되지 않는다. 그래서 이 두 중입자는 $\Omega_{c}$ 의 들뜬 $\Omega_{c}$ 라기 보다는 반 십오중항에 속하는 펜타쿼크 중입자라고 해석하는 이론 연구도 있다..$^{[12]}$ 반십오중항은 스핀이 각각 $1 / 2,3 / 2$ 인 두 개의 표현으로 다시 나뉘는데, 만약에 이 두 개의 $\Omega_{c}$ 가 각 각 스핀 $1 / 2,3 / 2$ 인 반십오중항에 속하는 중입자라면, 반드시 전하를 띤 $\Omega_{c}$ 도 존재하여야만 한다. 전하를 띤 $\Omega_{c}$ 가 존재하 는지는 향후 실험에서 밝혀질 수 있다.

펜타쿼크 $P_{c}$ 와 $\Omega_{c}$ 실험은 무거운 펜타쿼크가 많이 존재할 지도 모른다는 걸 암시하기도 한다. $J / \psi$ 와 양성자가 묶일 수 있다면, $\eta_{c}$ 나 다른 들뜬 차모니움과 양성자가 결합하는 경우도 생각해볼 수 있으므로 앞으로 무거운 펜타쿼크에 관한 연구가 활발해질 뿐만 아니라, 강입자 물리학 분야에서 별난 강입자가 중요한 위치를 차지하리라고 본다.

\section{테트라쿼크(Tetraquark) 중간자}

쿼크가 네 개로 이루어진 테트라쿼크 중간자가 흥미를 끈 건, 무거운 쿼크 영역에서였다. 2003년, KEK에 있는 Belle 실 험 그룹에서 지금까지 보지 못했던 새로운 차모니움을 발견하 였는데, ${ }^{[13]}$ 이 입자는 그때까지 발견된 차모니움과는 양태가 무 척 달랐다. 질량이 $3872 \mathrm{MeV}$ 였고, 붕괴폭은 $\Gamma<2 \mathrm{MeV}$ (신 뢰도 $90 \%$ )이었다. 붕괴폭이 몹시 작다는 사실은 다른 차모니 움과 구별되었다. 게다가 질량이 $D$ 중간자와 $\bar{D}$ 중간자의 질 량 합보다 컸다. 이 중간자에는 $X(3872)$ 라는 이름을 붙였다 (이 중간자의 발견에는 경상대 최수경 교수의 역할이 컸다). 이 입자를 어떻게 이해할 것인지는 의견이 분분한데, 현재까지는 $D(\bar{D})$ 중간자와 $\bar{D}^{*}\left(D^{*}\right)$ 벡터 중간자가 묶여있는 상태(이런 상태를 분자상태라고 부른다)와 일반적인 차모니움이 섞여 있 는 상태라는 견해가 우세하다. 그러니까 넓은 의미에서는 이 $X(3872)$ 는 테트라쿼크 중간자라고 부를 수 있다(좁은 의미로

\section{REFERENCES}

[9] M. J. Amaryan, Phys. Rev. C 85, 035209 (2012).

[10] LHCb Collaboration, Phys. Rev. Lett. 115, 072001 (2015).

[11] LHCb Collaboration, Phys. Rev. Lett. 118, 182001 (2017).

[12] H.-Ch. Kim, M. V. Polyakov and M. Praszalowicz, Phys. Rev. D 96, 039902 (2017).

[13] Belle Collaboration (S. K. Choi et al.), Phys. Rev. Lett. 91, 262001 (2003). 
는 두 중간자의 묶임 상태가 아니라 쿼크 네 개가 합쳐져야지 만 색소가 하얀색 또는 단일항이 되는 상태를 테트라쿼크 중 간자라고 부른다).

이 테트라쿼크 중간자에 관한 연구도 역사가 제법 오래되었 다. ${ }^{[14]}$ 앞에서 겔만이 쿼크 모형을 내놓을 때부터 제안되기는 했지만, 1970년대부터 1980년대에 스칼라 중간자 $f_{0}(980)$ 이 나 $a_{0}(980)$ 을 쿼크와 반쿼크 $(q \bar{q})$ 만으로 되어있는 입자라고 간 주하면, $\kappa$ 중간자와 더불어 이 입자들을 맛깔 $\mathrm{SU}(3)$ 표현에 따라 분석하는 게 쉽지 않고, 이론적으로 예측된 결과가 실험 값과도 다르다. 하지만 만약에 이 스칼라 중간자들이 4개의 쿼 크 $(q q \bar{q} \bar{q})$ 로 되어있거나 케이온과 반케이온 $(K \bar{K})$ 이 묶여있는 분자상태라고 해석하면, 실험값을 어느 정도 잘 설명할 수 있 다. 물론 여전히 이 중간자들의 내부 구조를 테트라쿼크인지 분자상태인지 두부 자르듯 명징하게 구분할 수는 없지만, 적어 도 이 중간자들의 구조가 단순히 쿼크 하나와 반쿼크 하나만 으로는 설명할 수 없다는 사실은 분명하다.

가벼운 쿼크로 이루어진 중간자보다는 오히려 맵시쿼크나 바 닥쿼크가 들어있는 경우가 테트라쿼크를 연구하기에는 더 낫 다. 그 이유는 무거운 쿼크의 질량이 대단히 무겁다고 생각하 면, 무거운 쿼크 스핀-맛깔 대칭성이라는 걸 도입할 수 있는데, 이 대칭성 때문에 많은 걸 단순하게 처리할 수 있다. 몇 가지 예를 들어보자. $D s(2317)$ 강입자는 $\mathrm{BaBar}$ 실험에서 가장 먼 저 발견되었는데, $\mathrm{CLEO}$, Belle 같은 실험에서도 그 존재가 검 증되었다. 이 강입자 역시 쿼크와 반쿼크 $(c \bar{s})$ 만으로는 그 성질 을 다 설명하지 못한다. 그래서 이 중간자가 $D \bar{K}$ 같은 분자 구조, 아니면 네 개의 쿼크로 되어있는 테트라쿼크 상태나 이 둘이 혼합되어있는 상태라고 생각할 수 있다.

앞에서 말한 $X(3872)$ 중간자의 발견은 무거운 테트라쿼크 중간자라는 새로운 분야를 활짝 열었다. Belle, BarBar, BES 실험에서 연이어 새로운 중간자를 발견하였는데, 이 입자를 총 칭해서 $X Y Z$ 중간자라고 부른다. 새롭게 발견된 이 무거운 중간자들은 모두 쿼크와 반쿼크만으로는 설명이 잘 안 되기 때문에 이 중간자들을 테트라쿼크나 분자 상태로 두는, 여러 가지 이론들이 나오고 있다.

앞에서 말한, Belle 실험에서 발견한 $X(3872)$ 는 $\mathrm{CDF}, \mathrm{D} 0$, $\mathrm{BaBar}, \mathrm{LHCb}$ 에서도 그 존재를 확인하였다. 이 중간자의 질량 은 $D^{0}$ 와 $D^{* 0}$ 의 질량을 합한 값과 매우 비슷하고, 붕괴폭은 $1.2 \mathrm{MeV}$ 보다 작다. $X(3872)$ 가 발견된 뒤, 이 입자가 붕괴하 는 채널을 살펴봤는데, 스핀이 1 인 별난 중간자거나 아니면 스 핀이 2 인 보통 중간자일 수도 있다는 걸 알아냈다. $X(3872)$ 가 발견된 지 10 년이 지나서야 비로소 $\mathrm{LHCb}$ 실험에서 스핀을 측정했는데, 이 중간자는 스핀이 1 인 별난 강입자라고 확증되
었다.

$X(3872)$ 특이 강입자가 발견된 뒤, 전하를 띤 별난 강입자 도 발견되었는데, 그 중 대표적인 입자가 Belle 실험에서 발견 한 $Z_{c}(4430)$ 이다. 이 중간자는 발견되고 나서 $\mathrm{BaBar}$ 에서 다 시 측정했는데, 발견에 실패한 입자다. 그러나 $\mathrm{LHCb}$ 실험에서 같은 입자를 발견하면서, $Z_{c}(4430)$ 이 존재한다는 게 확인되었 다. $\mathrm{LHCb}$ 는 $Z_{c}(4430)$ 말고도 질량이 비슷한 $Z_{c}(4240)$ 도 발 견하였다. 그리고 $Z_{c}(4050), Z_{c}(4250)$ 같은 중간자도 Belle에 서 관측하였다. 반면에 이들은 $\mathrm{BaBar}$ 에서는 보지 못하였기 때 문에 추가 실험을 해야만, 최종적으로 이들 입자의 존재여부가 검증될 것이다.

최근에는 $\mathrm{BES} \mathrm{III} \mathrm{실험에서} \mathrm{또} \mathrm{다른} \mathrm{무거운} \mathrm{중간자를} \mathrm{발}$ 견하였는데 이 중간자는 $Z_{c}(3900)$ 이라는 이름이 붙여졌다. 이 무거운 중간자는, $\mathrm{BES}$ III 실험에서 수행한 $e^{+} e^{-} \rightarrow$ $\pi^{+} \pi^{-} J / \psi$ 과정에 있는 $\pi \pm J / \psi$ 스펙트럼을 분석해서 관 측하였다. 그리고 Belle, CLEO 실험에서도 이 중간자가 존재 한다는 걸 검증하였고, 게다가 각운동량을 분석해서 이 중간자 가 스핀 1 인 벡터 중간자라는 사실과 홀짝성이 양이라는 사실 도 알아내었다. 하지만 최근에 격자 이론에서는 $Z_{c}(3900)$ 이 존재한다는 근거를 찾지 못했다. $Z_{c}(3900)$ 의 구조는 아마도

$D \bar{D}^{*}$ 분자 상태일 것이라고 여겨진다.

이 밖에도 바닥 쿼크를 포함한 새로운 강입자도 발견되었는 데, 맵시 쿼크를 포함한 강입자와 유사하게 그 이름이 붙여졌 다. 그 이유는 무거운 쿼크의 질량이 무한대로 가면, 강입자 안에 들어있는 무거운 쿼크가 맵시 쿼크든 바닥 쿼크든 상관 없기 때문이다. 이러한 성질을 무거운 쿼크의 맛깔대칭성이라 고도 부른다. 이 새로운 중간자 중에서 전하가 양이고, 스핀은 1 , 홀짝성은 +1 인 무거운 벡터 중간자 $Z_{b}^{+}(10610)$ 과 $Z_{b}^{+}(10560)$ 를 Belle 실험에서 가장 먼저 발견하였는데, 이 입자에 대응되는 전기적으로 중성인 중간자 $Z_{b}(10610)$ 도 관 측되었다. 맵시 쿼크가 들어있는 중간자와 마찬가지로 이 $Z_{b}$ 중간자의 질량은 $B$ 와 $B^{*}$ 또는 $B^{*} \overline{B^{*}}$ 질량합과 매우 비슷 하다. 이 말은 $Z_{b}$ 중간자가 $B \bar{B}^{*}$ 또는 $B^{*} \bar{B}^{*}$ 와 같은 분자 상태일지도 모른다는 해석의 근거가 된다. 물론 이런 별난 중 간자의 붕괴과정을 정밀하게 분석하면, 이들이 분자상태가 아 니라 테트라쿼크나 글루온과 쿼크가 같이 들어있는 하이브리드

\section{REFERENCES}

[14] R. L. Jaffe, Phys. Rev. D 15, 267 (1977), ibid, 15, 281 (1977). 
상태일 수도 있다. 이런 점에서 지금까지 발견된 별난 중간자 들이 어떻게 붕괴하는지 아는 건 몹시 중요하다.

별난 중간자 $X(3872)$ 에서 맵시 쿼크를 바닥 쿼크로 바꿔주 면, 이와 아주 비슷한 무거운 중간자를 만들어 볼 수 있다. 실 제로 $X(5568)$ 이라는, $X(3872)$ 와 닮은 별난 강입자가 최근에 발견되었다. $\mathrm{D} 0$ 실험에서는 에너지가 $5.6 \mathrm{GeV}$ 근처이고, 이 입자가 $B^{0}$ 와 $\pi$ 로 붕괴하는 과정에서 나타나는 질량 스펙트 럼을 분석해서 이 입자를 찾아내었다. 질량과 붕괴폭은 각각 $5567.8 \mathrm{MeV}$ 와 $21.9 \mathrm{MeV}$ 라고 알려졌지만, 스핀과 홀짝성은 아직 모른다. 이론적으로는 이 중간자의 파동함수가 $\mathrm{u}, \mathrm{b}, \mathrm{d}$, $\mathrm{s}$ 쿼크를 포함하므로, 쿼크 네 개로 이루어진 스칼라 중간자일 수도 있다고는 하지만, $\mathrm{LHCb}$ 에서는 이 중간자는 아직 찾지 못하였다.

이론적인 연구에서도 $X(5568)$ 중간자가 존재할지는 아직 결론이 나지 않았다. 이론물리학자들은 $\mathrm{QCD}$ 합산규칙, 재산란 효과, 짝을 이룬 경로 방법과 같이 다양한 방법을 이용해서 이 입자의 구조를 이론적으로 살펴보고 있다. 이 입자가 테트라쿼 크 상태나 분자 상태라고 간주하고 계산한 결과는 모두 실험 값과 일치하지 않았다. 만약에 이 중간자가 테트라쿼크 상태라 면, 질량이 지금보다 약 $200 \mathrm{MeV}$ 이상 커야 한다거나, 아니 면 질량이 $5200 \mathrm{MeV}$ 정도로 작아야 한다는 이론적인 연구도 있다. 반면에 색소 자기(chromomagnetic) 상호작용 효과를 고 려한 다체 쿼크 모형에서는 실험결과와 정확하게 일치하는 분 석을 내놓기도 했지만, 좀 더 타당한 결론을 내리려면, $X$ (5568) 중간자가 실험적으로 존재하는지, 그리고 존재할 경우 붕괴 채널은 어떻게 되는지 좀 더 자세히 연구해야 하고, 이론 적으로도 좀 더 엄밀한 방법을 이용하여 이 입자의 구조를 살 펴봐야만 할 것이다. ${ }^{[15-17]}$

\section{중간자-중입자 분자상태 $\wedge(1405)$}

현존하는 들뜬 중입자 중에서도 펜타쿼크나 중간자와 중입자 가 약하게 결합하여 만든 분자상태가 있는지 살펴보는 것 또 한 강입자 물리학에서 매우 중요한 연구주제다. 예를 들면, $N^{*}(1535)$ 가 $\eta$ 중간자와 핵자로 붕괴하는 게 거의 $50 \%$ 정도 된다는 사실은 $N^{*}(1535)$ 가 단순히 핵자를 이루는 입자가(粒 子價) 쿼크(valence quark) 중 하나가 들떠서 만들어내는 들뜬 핵자가 아니라는 걸 암시한다. 어쩌면 핵자 내부에 입자가 쿼 크 말고, 바다 쿼크(sea quark)가 에너지를 받아 들뜬 상태를 포함하고 있는 게 $N^{*}$ (1535)일 수도 있다. 또는 이 들뜬 핵자 는 쿼크 세 개로 된 상태와 바다 쿼크가 들뜬 상태가 혼합된 것일 수도 있다. 무거운 쿼크계와는 달리 가벼운 쿼크는 이론 적으로 다루기에 매우 까다로워서 좀 더 면밀하게 살펴봐야

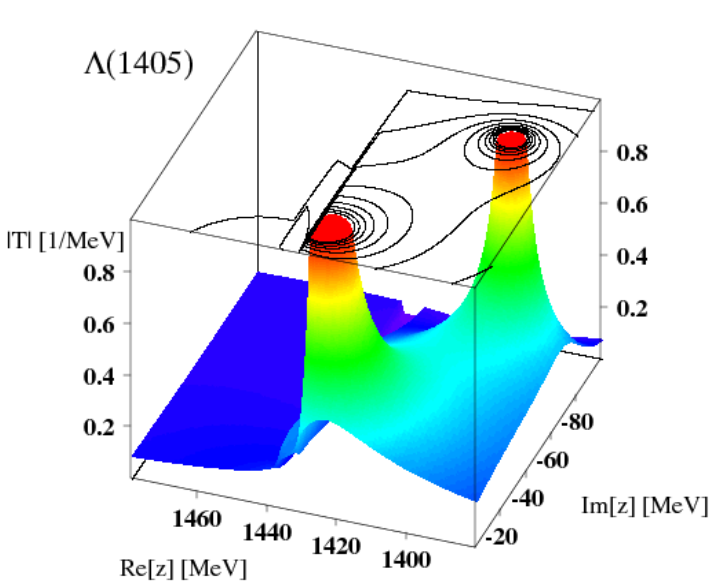

Fig. 3. Two-pole structure of the $\Lambda(1405)$ in the complex plane.

하는 문제다.

하이퍼론도 에너지를 받으면 들뜨는데, 첫 번째 들뜬 상태가 바로 $\Lambda(1405)$ 이다. 흥미롭게도 $\Lambda(1405)$ 의 질량 스펙트럼은 보통 중입자와는 달리 가우스 형태의 분포를 보이지 않고 상 당히 비대칭적인 양태를 보인다. 그래서 $\Lambda(1405)$ 는 단순히 쿼 크 세 개로 이루어진 보통 중입자가 아니라 중간자-중입자 분 자상태일지도 모른다. ${ }^{[18]}$ 이런 상태가 존재하려면, 중간자와 중 입자가 묶일 수 있는 메커니즘이 필요한데, 이것을 설명하는 이론 중 하나가 손지기 역학(chiral dynamics)이다. 손지기 섭 동론을 이용하여 이론적으로 계산한 이 들뜬 하이퍼론의 전하 반지름(charge radius)이 보통 중입자보다 상당히 크고, 붕괴 하는 과정도 보통 중입자와는 제법 다르다. 게다가 $\Lambda(1405)$ 가 쿼크 세 개로 된 들뜬 중입자라고 하면, 상대론적 쿼크 모형과 격자 $\mathrm{QCD}$ 에서 계산한 질량이 약 $1600 \mathrm{MeV}$ 가량 된다. 이 값은 실험값보다 약 $200 \mathrm{MeV}$ 정도 무겁다. 따라서 $\Lambda(1405)$ 의 구조가 보통 중입자와는 다르다고 보는 게 좀 더 타당해 보인다. 물론 $\Lambda(1405)$ 를 보통 중입자의 들뜬 상태라고 보는 연구 그룹도 있고, 쿼크 다섯 개로 이루어진 펜타쿼크라고 말 하는 데도 있고, 그 외에도 여러 모형이 있지만, 현재까지 산 란실험, 격자 $\mathrm{QCD}$ 연구, 유효이론 계산을 고려하면, $\Lambda(1405)$ 를 중간자-중입자 분자상태로 간주하는 게 가장 적당해 보인 다. 실제로 $\Lambda(1405)$ 의 구조를 잘 설명하는 이론 중 하나인 손 지기-유니터리 모형을 이용하면, $\Lambda(1405)$ 가 보통 공명 상태처

\section{REFERENCES}

[15] A. Esposito et al., Int. J. Mod. Phys. A 30, 1530002 (2015).

[16] H.-X. Chen, W. Chen, X. Liu and S.-L. Zhu, Phys. Rept. 639, 1 (2016).

[17] F-K. Guo et al., Rev. Mod. Phys. 90, 015004 (2018).

[18] T. Hyodo and D. Jido, Prog. Part. Nucl. Phys. 67, 55 (2012). 
럼 산란 이론에 따라 제 2 리만 평면에 단일극으로 해석하는 것 보다는 그 평면 위에 있는 두 개의 극으로 이루어진, 매우 복 잡한 구조를 띤 중입자라고 해석할 수 있다. 그림 3에서 보여 주듯이 $\Lambda(1405)$ 는 마치 두 개의 공명 중입자가 겹쳐진 것 같 이 보인다.

물론 $\Lambda(1405)$ 를 공명 입자 하나로 간주해도 $\Lambda(1405)$ 의 성 질을 잘 설명할 수 있다는 이론도 있다. ${ }^{[19]}$ 이 첫 번째 들뜬 하이퍼론의 구조를 이해하는 건 여전히 현재진행형이다. 산란 이론 관점에서만 보면 이 하이퍼론의 내부 쿼크 구조가 어떤 지 살펴보는 게 쉽지 않기 때문에 좀 더 정량적인 쿼크 모형 이나 격자게이지 이론을 이용해 $\Lambda(1405)$ 를 제대로 이해하는 것도 강입자물리학에서는 몹시 중요한 문제로 남아있다.

들뜬 중입자의 구조는 논의된 지 이미 60여 년이 되었지만, 아직도 잘 모른다. 지금 존재하는 쿼크 모형 중에서 $N^{*}(1535)$ 와 로퍼(Roper) 공명 핵자 $N^{*}(1440)$ 의 질량 크기의 순서를 이론 적으로 모순 없게 설명하는 모형은 아직 없다. 게다가 대부분 의 쿼크 모형이 $\mathrm{SU}(6) \otimes \mathrm{O}(3)$ 대칭성에 기반을 두고 있는데, 이 대칭성의 크기가 너무 크기 때문에 실험에서 발견한 핵자, 델타 아이소바, 하이퍼론보다 훨씬 더 많은 수의 들뜬 중입자 가 존재한다고 예측한다. 실험 사실과 이론 예측이 서로 충돌 하는 이 문제는 “분실된 공명"(missing resonances)이라는 이 름으로도 잘 알려진 난제이다.

이 문제를 해결할 수 있는 열쇠는 어쩌면 별난 중입자가 쥐 고 있는지도 모른다. $N^{*}(1535)$ 도 $\Lambda$ (1405)도 그렇듯이 세 개 의 입자가 쿼크에 쿼크와 반쿼크가 더해진 구조를 고려하면, 질량 순서 문제라든가, 분실된 공명 입자 문제를 해결할 가능 성도 있다. 그리고 들뜬 중입자와 별난 중입자를 이해하는 데 뺄 수 없는 것이 쿼크의 갇힘 문제(quark confinement)다. 이 문제는 비섭동 양자색소역학 문제 중에서도 가장 어려운 문제 이고, 수학에서도 엄청난 관심이 있어 클레이 수학연구소에서 백만 불 상금까지 걸어놓은 10 대 문제 중 하나다. 핵자 안의
쿼크가 에너지를 받아도 여전히 핵자 안에 머물러 있거나 진 공에서 생겨난 다른 반쿼크와 쿼크가 또는 반쿼크가 쿼크와 결합해 중간자를 방출하는 메커니즘은 아직 잘 모르지만, 들뜬 중입자 문제는 이토록 어려운 문제에 실마리를 제공해 줄 수 도 있다.

\section{맺음말}

별난 강입자는 “물질이란 무엇인가?”라는 웅장한 질문에 답 하려면 반드시 알아야 하는 입자다. 네 가지 힘 중에서 물질을 이루는 데 가장 중요한 힘인 강력을 이해하려면, 강입자를 이 루고 있는 쿼크와 글루온의 동역학을 알아야 한다. 그러나 강 입자의 본질은 비섭동적이기 때문에 우리가 잘 알고 있는 섭 동 양자색소역학만으로는 강입자를 다 이해할 수 없다. 결국, 격자 게이지 이론이나 유효장이론, 또는 인스탄톤이나 자기홀 극 같은 위상수학적인 개념들, $\mathrm{QCD}$ 합산규칙처럼 비섭동적인 부분을 섭동적인 부분에서부터 고립시켜서 다루는 방법들, 아 니면 게이지이론과 아인슈타인 중력이론 사이의 관계를 이용한 비섭동적 방법들, 또는 현상론적인 방법들과 같이 다양한 이론 적인 방법을 사용하여야만 한다. 그리고 $\mathrm{LHC}$, 제퍼슨 연구소, 일본 고에너지 연구소, SPring-8, J-PARC, 독일에 있는 ELSA, MAMI, FAIR, 중국의 BES III 실험과 긴밀하게 협업을 해야 하는 것 또한 별난 강입자를 이해하는 데 뺄 수 없는 요 소 중 하나다. 별난 강입자의 구조를 이해하는 것은 양자색소 역학의 난제 중 난제로 남아 있는 쿼크 갇힘 문제를 이해하는 데도 실마리를 제공해 줄 수 있는, 물리학 전체에서도 대단히 중요한 주제다.

\section{REFERENCES}

[19] D. Jido, et al., Phys. Rev. C 66, 055203 (2002). 